\section{Igor Guatelli}

Orientador:

Profa. Dra. Leyla Perrone-Moisés

\author{
ONTAMINAÇÕeS CONSTITUTIVAS \\ DO $e$ SPAÇO $u$ RBANO: C $u$ LT $u$ RA \\ uRBANA POR INTeRMéDIO DA

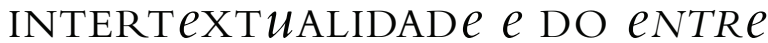

\title{
ResUMO
}

Segundo Perrone-Moisés, professora emérita de literatura francesa da Universidade de São Paulo (USP), entende-se por intertextualidade esse trabalho constante de cada texto com relação aos outros, o imenso e incessante diálogo entre obras que constitui a literatura. Cada obra surge como uma nova voz (ou um novo conjunto de vozes) que fará soar diferentemente as vozes anteriores, arrancando-Ihes novas entonações - diálogo infinito/obra inacabada.

O conceito de intertextualidade, advindo da literatura, é aplicável também na filosofia, como tem demonstrado Derrida em suas obras. A intertextualidade, o entre textos, um espaço de intermediação entre diferentes vozes, um espaço surgido do diálogo entre diferentes obras, textos, não necessariamente pertencentes a uma mesma época histórica ou ao mesmo gênero, torna-se, para Derrida, um poderoso instrumento à desconstrução do que parece ser dominante e natural. Igualmente, entende-se por entre, um intervalo, um espaço em latência e a-significante, ao mesmo tempo presente e ausente, entre presenças, em trânsite, sempre aberto ao porvir e pronto para ser fecundado, ao se manter apenas como um espaço de intermediação entre o suporte (seja ele uma escritura derridiana ou uma arquitetura infra-estrutural) e o usuário criador.

Falando especificamente do espaço urbano, tais conceitos se tornam importantes nas discussões sobre a constituição de um espaço-suporte. Como nos textos, não se trataria simplesmente do vazio des-programado, mas um espaço, ao mesmo tempo, consistente e "esvaziado".

Trabalhado como espaço de intermediação entre diferentes ações (a partir de diferentes vozes), por vezes com intenções conflitantes e distantes do que poderia ser apropriado para o correspondente lugar, esse espaço possibilitaria o engendramento de incessantes desterritorializações e reterritorializações do lugar, atribuindo-Ihe, assim, diferentes sentidos e significados (entonações) ao desestabilizar sua representação.

Com isso, propõe-se indagar se a consideração de tais conceitos favoreceria uma condição fundamental ao que poderíamos entender como uma chance para o advento de novas humanidades. Seriam, talvez, humanidades expressas na possibilidade, potencializada pela arquitetura e urbanismo, de ir além do estipulado e determinado, especialmente para aqueles que não querem apenas o lugar que thes foi destinado ou o que este lugar sugere como mais apropriado. Em uma perspectiva desconstrutora, busca-se um diálogo fecundo com a filosofia pósestruturalista, sobretudo de Derrida, e com a literatura, principalmente de Barthes, e, ao mesmo, transgredir as barreiras que limitam o raciocínio projetual. 0 artigo se debruça sobre uma situação limite e atípica encontrada na cidade de São Paulo; a saber, a constitutiva ocupação dos baixos do viaduto do Café, com o propósito de pensarmos problematicamente essa diferença e, com isso, formular questões sobre o im-possível outrem da cultura urbana atual.

\section{Palavras-Chave}

Contaminações, incubadores urbanos, entre, intensidade, urbanismo informal. 


\section{Contaminaciones Constitutivas Del ESPACIO URBANO: CULTURA URBANA A TRAVÉS DE LA INTERTEXTUALIDAD Y DEL CONCEPTO DE "ENTRE"}

\section{RESUMEN}

Según Perrone-Moisés, profesora emérita de literatura francesa de la Universidade de São Paulo (USP), se entiende por intertextualidad el trabajo constante de cada texto en relación con los demás, el inmenso e incesante diálogo entre obras que constituye la literatura. Cada obra surge como una voz (o un nuevo conjunto de voces) que hará sonar de manera diferente las voces anteriores, sacándoles nuevas entonaciones - diálogo infinito/obra inacabada.

El concepto de intertextualidad, procedente de la literatura, se puede aplicar también en la filosofía, como ha demostrado Derrida en sus obras. La intertextualidad, el "entre textos", un espacio de mediación entre distintas voces, un espacio que surgió del diálogo entre distintas obras, textos, no necesariamente de la misma época histórica o del mismo género, se vuelve, para Derrida, un poderoso instrumento para la desconstrucción de lo que parece ser dominante y natural. Igualmente, se entiende por "entre" un intervalo, un espacio latente y no-significante, presente y ausente a la vez, entre presencias, en tránsito y siempre abierto al porvenir, listo para ser fecundado, al mantenerse tan solo como un espacio de mediación entre el soporte (ya sea una escritura derridiana o una arquitectura infraestructural) y el usuario creador. Para hablar específicamente del espacio urbano, esos conceptos se hacen importantes en las discusiones sobre la constitución de un "espacio soporte". Así como en los textos, no se trataría simplemente del vacío desprogramado, sino de un espacio, al mismo tiempo, consistente y "vaciado". Al ser trabajado como espacio de mediación entre distintas acciones (a partir de distintas vocês), por veces con intenciones conflictantes y distantes de lo que podría ser apropiado para el lugar correspondiente, ese espacio posibilitaría la concepción de incesantes desterritorializaciones y reterritorializaciones del lugar, atribuyéndole así distintos sentidos y significados (entonaciones) al desestabilizar su representación. Con eso, se propone indagar si la consideración de tales conceptos favorecería una condición fundamental para lo que podríamos entender como una oportunidad para el advenimiento de nuevas humanidades. Serían, quizás, humanidades expresas en la posibilidad, potenciada por la arquitectura y el urbanismo, de ir más allá de lo que fue estipulado y determinado, en especial para aquellos que no quieren solamente el lugar que les fue destinado o aquello que ese lugar sugiere como más adecuado. Bajo una perspectiva desconstructora, se busca un diálogo fecundo con la filosofía postestructuralista, sobre todo de Derrida, y con la literatura, principalmente de Barthes, y, a la vez, la transgresión de las barreras que limitan el raciocinio proyectual. El artículo se reclina sobre una situación límite y atípica encontrada en la ciudad de São Paulo, es decir, la ocupación constitutiva de los bajos del Viaducto del Café, con el propósito de pensar problemáticamente esa diferencia y, con eso, formular cuestiones sobre lo im-posible ajeno de la cultura urbana actual.

\section{Palabras clave}

Postestructuralismo, entre, intertextualidad, urbanismo informal, creación, inesperado, contaminación. 


\section{Constitutive CONTAMinations of THE URBAN SPACE: URBAN CULTURE THROUGH INTERTEXTUALITY AND THE IN-BETWEEN}

\section{ABSTRACT}

According to Perrone-Moisés, emeritus professor of french literature at University of São Paulo (USP), intertextuality should be understood as the constant work of each text as related to others, this huge and unceasing dialogue among the works that constitute the literature. Each piece of work presents itself as a new voice (or a new set of voices) that will make the previous voices sound different, leading to infinite dialogue/unfinished work. The concept of intertextuality in literature also applies to philosophy, as shown by french philosopher Jacques Derrida in his writings. Intertextuality, or the in-between texts, a space of intermediation among different voices or a space resulting from the dialogue among different works and texts not necessarily belonging to the same historical time or genre is, according to Derrida, a powerful tool for the deconstruction of what seems to be dominant and natural. Likewise, the in-between is considered an interval, or a space of latency, where it is at the same time present and absent, between presences and, therefore, ready to be fertilized and open to that to come while it is kept merely as a space of intermediation between the support (whether one of Derrida's writings or a piece of architecture) and the user creator. Specifically regarding urban spaces, such concepts have become very important when discussing the constitution of a support space. As described in the literature, it would not be merely about a de-programmed emptiness, but a space at the same time consistent and "emptied". If worked as a space of intermediation among different actions (as from different voices), sometimes with conflicting intentions far from what would be appropriate for the corresponding location, it would engender new possibilities, possibilities of unceasing de-territorialization and re-territorialization of such location. Therefore, we question whether the consideration of such concepts would favor a fundamental condition to what we could understand as a chance for the advent of new humanities. They would probably be humanities expressed in the possibility potentialized by architecture and urbanism, going beyond what is stipulated and determined, especially for those who do not merely want the locations destined to them. In a de-constructive perspective, we look for a dialogue with post-structuralist philosophy, especially that of Derrida, and with the literature, mainly Roland Barthes, and, at the same time, attempt to trespass the barriers which limit project reasoning. This article addresses a limit situation found in the city of São Paulo, namely the constitutive occupation of the lower part of Viaduto do Café, an overpass, so as to formulate questions about the impossible other of the current urban culture.

\section{KEY WORDS}

Post-structuralism, in-between, inter-textuality, potentialization, invention, unexpected, constitutive contamination. 


\section{INTRODUÇÃO}

(1) "Tout texte se construit comme mosaïque de citations, tout texte est absortion et transformation d'un autre texte. À la place de la notion d'intersubjectivité, s'installe celle d'intertextualité." KRISTEVA, Julia. Sémeiotiké-recherches pour une sémanalyse. Paris: Seuil, 1969, p. 146.

(2) PERRONE-MOISÉS, Leyla. Texto, crítica, escritura. São Paulo: Ática, 1993, p. 63.
Partindo das teorias do semioticista russo Mikhail Bakhtine, Julia Kristeva cunhou o conceito de intertextualidade, dizendo que todo texto é absorção e transformação de uma multiplicidade de outros textos, ou "todo texto se constrói como um mosaico de citações, todo texto é absorção e transformação de um outro texto. No lugar da noção de intersubjetividade se instala a de intertextualidade"1. Perrone-Moisés afirma: "entende-se por intertextualidade esse trabalho constante de cada texto com relação aos outros, esse imenso e incessante diálogo entre obras que constitui a literatura. Cada obra surge como uma nova voz (ou um novo conjunto de vozes) que fará soar diferentemente as vozes anteriores, arrancandoIhes novas entonações - diálogo infinito/obra inacabada. "

O conceito de intertextualidade, na literatura, é aplicável também na filosofia, como tem demonstrado Derrida em suas obras. Como podemos depreender das palavras de Kristeva e Perrone-Moisés, a intertextualidade é um espaço de intermediação entre diferentes vozes, um espaço surgido do diálogo entre diferentes obras, textos, não necessariamente pertencentes a uma mesma época histórica. Falando especificamente do espaço urbano, poderíamos discutir sobre o espaço de intermediação entre diferentes ações (a partir de diferentes vozes), com intenções conflitantes que poderiam engendrar novas possibilidades de desterritorializações e re-territorializações.

Por meio desse "processo" da intertextualidade, surge um espaço no qual a constituição de uma concatenação hierárquica do discurso, ou de uma autoridade e autonomia de um texto sobre outro(s), entendidos aqui como intenções programáticas e determinações de desenho definidos pelo arquiteto, não é mais possível; o centro, ou centros, antes localizados justamente nos textos, desloca-se para essa zona intermediária, para esse espaço entre os textos e a relação; "o diálogo" que se estabelece entre os textos passa a prevalecer sobre a unidade discursiva, antes inviolável, de cada texto.

Muito próximo do que chamamos de transdisciplinaridade, a intertextualidade, nesse processo de inter-relação entre obras, abre a possibilidade para que a unidade (transcendental) de um edifício teórico não seja mais concebida a priori ou que o discurso esteja atrelado a um princípio-guia capaz de influenciar, direcionar, conduzir, ou encerrar as expressões posteriores advindas, de certa forma inibindo a criação, particularmente na arquitetura, campo de nossa pesquisa. 
(3) BARTHES, Roland. Le plaisir du texte. Paris: Éditions du Seuil, 1973.

(4) PERRONE-MOISÉS, Leyla. Op. cit., p. 60.

(5) Idem, ibidem, p. 70

(6) Idem, ibidem, p. 61.
No campo da literatura, como no da filosofia, e, por que não, em arquitetura, tradicionalmente vemos uma preocupação discursiva com a explicitação, explicação, avaliação (propriedades transitivas) do objeto, uma tendência à unificação final do sentido, objetivando, talvez, sua permanência e sua transformação em referência, conduzindo a leituras homogeneizadoras, previsíveis.

Ao contrário, com a intertextualidade, onde antes tínhamos a prevalência da estabilidade, do absoluto, da hierarquia, da legibilidade, do discurso dominante, esses dão lugar a um objeto híbrido, a uma estrutura não-centrada aberta à ambigüidade, à ambivalência dos sentidos, aos paradoxos, à instabilidade das certezas antes tomadas como verdades inquestionáveis.

Inaugura-se, assim, uma fase em que passam a prevalecer o intersticial, as interseções, o entre, constituindo-se um campo muito fértil às experimentações, às apropriações livres, ao evento, à criação e à jouissance ${ }^{3}$, pois seu objetivo não é sua validação por intermédio da explicação de outros textos, mas sua própria produção, aberta à infinidade e ao não-esgotamento, sempre em processo, sempre por vir - discutiremos melhor esses aspectos à luz da arquitetura -, "sem que se vise ao estabelecimento de um sentido final - coincidente ou contraditório com o sentido incorporado"4.

Porém, ainda seguindo Perrone-Moisés, o que temos, tradicionalmente, nos campos das linguagens (literatura, filosofia e, como podemos perceber também, na arquitetura) ainda é uma prevalência do que conhecemos por metalinguagem, uma linguagem "que tem por objetivo explicitar uma outra linguagem (...) Não podemos imaginar uma metalinguagem de tipo lógico que deixe suspensos os sentidos, que se permita reticências, sugestões inconscientes ou sensoriais, que assuma em sua própria textura os não-ditos do inconsciente, suas perdas incalculáveis, que favoreça a proliferação indefinida dos sentidos"s.

Por essa perspectiva, o que historicamente estaria ligado a uma tendência de institucionalização e compartimentação do saber segundo os moldes acadêmicos - separação entre as disciplinas científicas e artísticas, por exemplo com a formatação, e institucionalização de um discurso no qual a busca por um significado era fundamental, no qual, segundo novamente Perrone-Moisés, "o sentido geral convergia para uma significação prioritária (discurso monológico) com a intertextualidade, a necessidade de uma unificação coerente final dá lugar a uma "intercambialidade".

Entenderíamos, assim, essa "intercambialidade" como deslocamentos constantes e pluralidade dos significados e sentidos possibilitados por um cruzamento intenso de diversos textos, distantes no tempo, diferentes no gênero, nas prerrogativas, nos objetivos, estimulando, dessa forma, a formação de um saber em constante processo, alimentado por incessantes elaborações e reelaborações concretizadas, justamente, pelas múltiplas relações, baseadas não em causalidades ou continuidades e concatenações dos significados e sentidos entre textos, mas nas transgressões desses sentidos, nos devires que podem surgir dos cruzamentos entre as obras, as linguagens, sejam elas artísticas ou científicas.

Não estaríamos falando aqui justamente de uma posição adotada por certos arquitetos, muito próxima daquela adotada pelos escritores na literatura? Vide, por exemplo, tanto a produção artística como teórica de arquitetos como Peter 
(7) EISENMAN, Peter. Diagram diaries. Londres, Thames \& Hudson, 1999; Processos de lo intersticial. El Croquis, Madri, n. 83, 1997, p. 2135; An architectural design interview by Charles Jencks. Architectural Design Deconstruction in Architecture. Nova York: Academy Group LTD, v. 58, 1998, p. 49-61.

(8) Cf. DERRIDA, Jacques. ver Khôra/La Verité en Peinture/De la grammatologie.

(9) BARTHES, Roland. Le plaisir du texte. Paris: Éditions du Seil, 1973.

(10) PERRONE-MOISÉS, Leyla. Op. cit., p. 61.
Eisenman ${ }^{7}$ e Bernard Tschumi, e seus estreitos vínculos com a lingüística e a filosofia. Talvez possamos dizer que, com a intertextualidade, a existência da humanidade não mais estaria vinculada à incessante tarefa de perseguir sua essência por suas diferentes e compartimentadas formas do pensar e do ser.

Entretanto, falamos até o momento de uma intertextualidade mais vinculada à idéia "imaterial" de um espaço de intermediação - entendido como estratégia potencializadora e detonadora de um processo de cruzamento entre diferentes e diversos textos, discursos, linguagens - do que propriamente à constituição de um espaço "material" (tome-se aqui esse termo em sua dimensão arquitetônica, ou seja, relativo às "situações" afeitas à arquitetura como interior/exterior, público/ privado). E se, a partir desse momento, passássemos a chamar esse espaço de intermediação, aplicável às obras literárias em seu sentido imaterial, de espaço intermediário, ou de entre da arquitetura, ou seja, um espaço material, pois constituído a partir das relações entre interior e exterior? Apesar de o próprio Derrida ter deixado claro, certa vez, que arquitetura é construção, material, correspondências podem ser estabelecidas entre os espaços de intermediação literário e arquitetônico ${ }^{8}$.

Em Le plaisir du texte, Barthes faz uma distinção entre o que chama de texto de prazer e texto de gozo (jouissance, mencionado acima), sendo o primeiro aquele que contenta, preenche, concede euforia, aquele que vem da cultura, não rompe com ela, está ligado a uma prática confortável da leitura, e, o segundo, aquele que coloca em estado de perda, que desconforta, faz vacilar os alicerces históricos, culturais, psicológicos do leitor, a consistência de seus gostos, de seus valores, de suas lembranças, que põe em crise sua relação com a linguagem ${ }^{9}$.

Se atentarmos para essas duas definições, veremos, claramente, as correspondências existentes entre essa diferenciação de Barthes sobre o texto e as discussões acerca dos discursos monológicos e a intertextualidade - condição ao que Perrone-Moisés denomina discurso dialógico, no qual "a palavra tende a ser bivocal ou polivocal, estabelecendo múltiplos contatos no interior do mesmo discurso ou com outros discursos"10.

$\mathrm{Na}$ história da arquitetura sabemos que o arquiteto quase sempre cumpriu um papel de definidor dos espaços e usos que estes deveriam abrigar. Difícil imaginar algo muito diferente desse papel a ele outorgado; afinal, adequar espaços "ao morar", no sentido amplo do termo, sempre foi uma prerrogativa da profissão.

A questão talvez se evidencie no momento em que esses espaços passaram de respostas aos anseios e necessidades do momento para se tornarem referências arquitetônicas evidentes, ou seja, soluções que passaram a ser utilizadas como premissas projetuais adotadas acritica e indiscriminadamente.

Disso advêm algumas questões correlatas: todas as pessoas se apropriam e percebem o espaço, ou a forma, da mesma maneira? Como o arquiteto pretende que elas percebam ou se apropriem dele? É possível o arquiteto determinar que exista uma forma adequada para cada tipo de uso, imaginando uma uniformização da percepção formal e espacial e uma estandardização dos movimentos das pessoas nesse espaço? Os espaços tradicionalmente identificados como espaços de circulação na cidade, como um viaduto ou ponte, por exemplo, utilizados como lugar de encontro ou local de lazer por praticantes de certos esportes radicais ou desejam estruturar locais de atividades, públicos e gratuitos ou não, parecem 

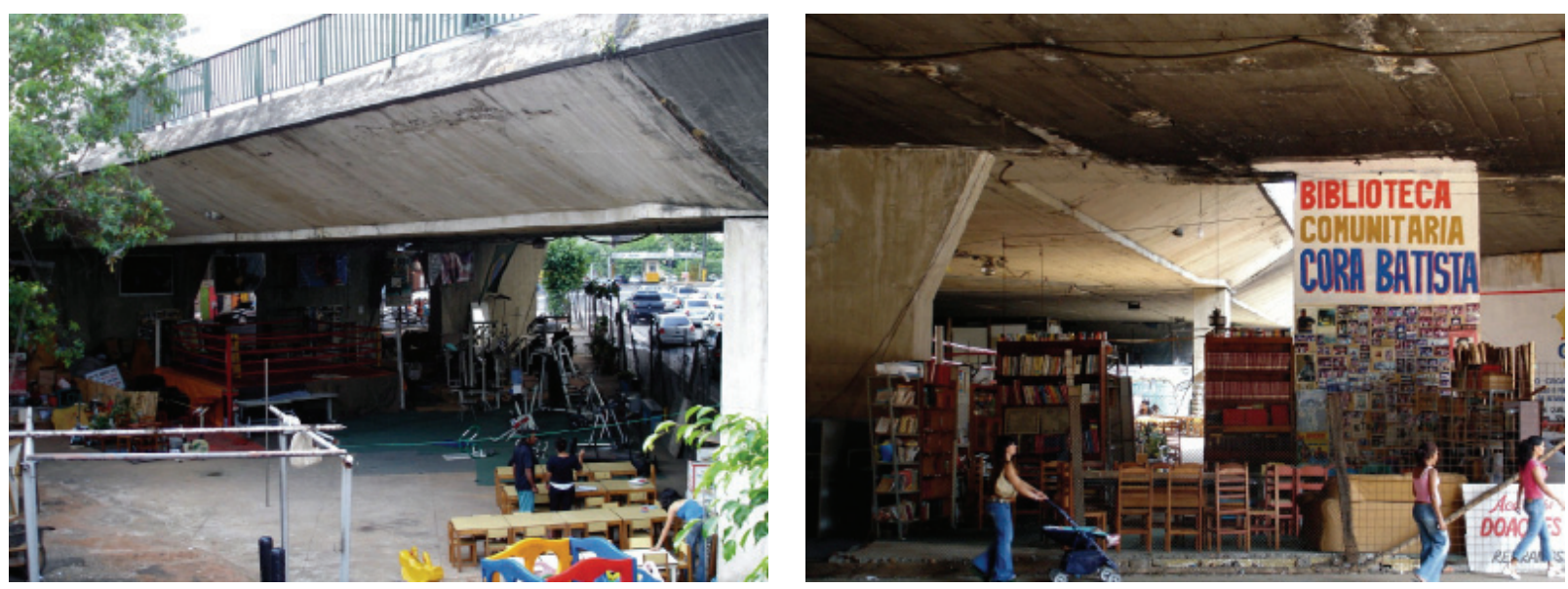

Figuras 1 e 2: Viaduto do Café, Contaminação constitutiva Academia, boxe, pré-escola e biblioteca. Espaço suporteReprogramações - Praças esportiva e cultural - São Paulo

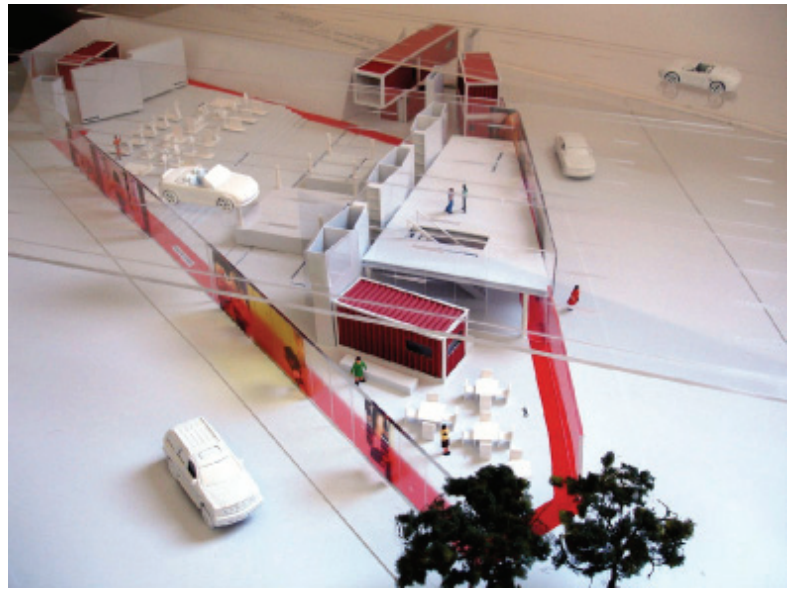

Figura 3: Vista aérea do conjunto: apoios do viaduto dividem a área em duas praças: praça cultural na parte frontal e esportiva na porção posterior. Mezanino multifuncional proporciona um espaço de leitura, computadores, curso de dança ou uma ocasional danceteria em finais de semana. Crédito: Projeto Intervenção sob o viaduto do Café, criado pelo Prof. Dr. e arquiteto Igor Guatelli (professor da FAU-Mackenzie), São Paulo, 2007. Equipe: Arquitetas Olívia Fontanetti, Natalia Gandini e Fernanda Lima Sakr

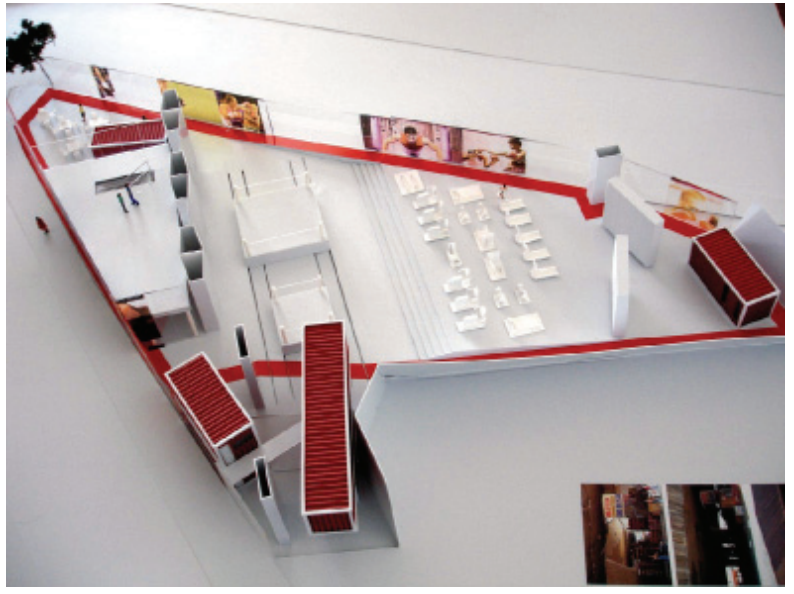

Figura 4: Facilmente deslocáveis, os ringues deslizantes no centro possibilitam reconfigurações momentâneas do espaço. Os ringues móveis se justificam em função de certas exigências programáticas: constituição de uma praça de eventos, com o ringue maior ocupando o centro, ou a liberação de uma área de carga e descarga de doações em uma faixa entre o mezanino e os contêineres. Dois grandes arquivos pivotantes separam e integram o espaço de ginástica da área para cursos técnicos nos fundos da área 
demonstrar que não. Como exemplo concreto, podemos citar o caso do exboxeador amador Nilson Garrido (Figuras 1 e 2).

Conhecido nacionalmente, motivo de reportagens e tema de publicações, Garrido, "administrador" da Academia de Boxe Cora Garrido, localizada sob o viaduto do Café em São Paulo, aponta-nos uma possibilidade no processo de contaminações constitutivas de espaços residuais urbanos centrais associados às estruturas existentes a partir de um trabalho voluntário (vontade de atuar).

Moradores do lugar, por não terem lugar, Garrido e sua companheira, Cora Batista, minam a representação (o que aquilo apenas representa, o ser fraco, o espectro, o fantasma) e "identidade original" de um local (não-lugar?) historicamente indesejável e condenável ao criarem e estruturarem um lugar esportivo e cultural hospitaleiro, um centro de ressocialização, composto por uma academia de ginástica, ringues de boxe, além de uma biblioteca e escola infantil, ou seja, uma praça esportiva e cultural, pública e gratuita. Pleiteando registro para atuar como uma ONG, tem procurado estabelecer, em acordo verbal, uma parceria com o poder municipal para disseminar suas "praças" por mais alguns locais semelhantes na cidade, gerando intensidades (diferencial qualitativo) sob viadutos, metamorfoseando-os, não aceitando e submetendo-se à representação que esses espaços adquiriram ao longo do tempo.

Ao contrário de estratégias (de negação) baseadas em impedimentos, falsos embelezamentos, esvaziamentos e inibições, o que vemos é a potencialização de um espaço-suporte, agora de acolhimento social incondicional, estimulante à ocupação produtiva, gerada por uma congestão e "promiscuidade" programáticas, de contigüidade e concomitâncias de atividades não-complementares; afinal, o que, historicamente, há em comum entre uma biblioteca, brinquedoteca e um ringue de boxe? Assim, indaga-se: corromper o "sentido" dado de algo para modificá-lo ou negá-lo?

Em um projeto arquitetônico para o improvisado local (Figuras 3 e 4), optouse por acentuar a dupla condição do local pela criação de um lugar de multiplicidades. Mais que procurar estabelecer relações com um contexto específico (contextualidade), no caso, o tradicional bairro Bela Vista, ou explorar linhas de irradiação além-território, optou-se por trabalhar a intertextualidade, ou seja, acentuar e reforçar os conflitos e relações programáticos e espaciais ali existentes, internos à área. Entende-se que o aprimoramento e fortalecimento das tensões e conflitos entre programas não-afins-intertextos, são vitais para a gestação de algo mais fecundo e intenso no local (incubador).

Combinando espaços de maior especificidade programática, como biblioteca e brinquedoteca, com espaços mais fluidos, de maior liberdade de ação e possibilidades de reconfigurações momentâneas, e que poderíamos denominar de arquitetura infra-estrutural, uma arquitetura não mais vista como um objeto independente, cenográfico, mas um subobjeto (subjétil), um suporte de interrelações, uma estrutura de suporte e potência, potencializadora de um porvir. Ringues de boxe deslizantes em trilhos, flexibilizando seus posicionamentos conforme as exigências de momento, degraus como arena, arquivos pivotantes, espaço em platôs, contêiner-parlatório, combinações infra-estruturais que tentam garantir um espaço estimulante às ocupações espontâneas e eventuais. Amplificar a vibração do lugar, mais que desenhar formas, busca-se evidenciar, com o 
(11) TSCHUMI, Bernard. Architecture and disjunction. Cambridge: The MIT Press, 1996.

(12) TSCHUMI, Bernard. Idem, ibidem, p. 176. projeto, a premência de espacializar-se força e intensidade para além de imagens e belas formas.

Apostando em uma estratégia projetual baseada na intertextualidade, nas relações entre funções díspares e não-afins, o projeto pretende reforçar a dicotomia ali existente entre o espaço suporte e lugar urbano, com uma arquitetura mais coreográfica que cenográfica, na qual o espaço ótico dá lugar ao espaço do movimento.

Seguindo Bernard Tschumi e seus questionamentos acerca da arquitetura, em sua obra Architecture and disjunction ${ }^{11}$, é possível dizer que existe uma linguagem coerente, ajustada e estável do espaço? Ou o espaço poderia desestabilizar e/ou superar suas representações e destinações, adquirindo significados e sentidos outros, imprevisíveis, a partir de inusitadas e acidentais apropriações? Inversamente, é possível pensar em uma arquitetura composta apenas por espaços in process, ou seja, espaços não determinados por seus possíveis usos? Seria possível uma arquitetura apenas de entres, de espaços residuais e intersticiais? Sem a pretensão de buscar uma resposta para cada uma dessas perguntas, utilizaremos as mesmas perguntas como balizadoras de nossas indagações, leituras e questionamentos acerca do espaço, arquitetônico e urbano.

A história dominante da arquitetura, baseada em história de significados constantemente reinterpretados (ordens, hierarquia, unidade compositiva, perspectiva axial), mas não questionados quanto à sua necessidade ou não, tem sido revista já há algum tempo por esses arquitetos próximos ao pensamento desconstrucionista, que passaram a questionar a validade dessas regras de composição e, sobretudo, a relação de causa e efeito entre significante e significado, entre forma proposta e apropriações advindas.

Como diz Tschumi, "muitos anos antes dos questionamentos levantados pelos arquitetos desconstrucionistas acerca da necessidade de uma relação causal entre forma e função, Jacques Lacan já indicava que não havia relação de causa-efeito entre significante e o significado, entre a palavra e o conceito pretendido"12. 0 significante não teria de responder, por sua existência, a uma hipotética significação. Como na literatura, ou na filosofia, e segundo Derrida, o significante arquitetural não necessita ser representado por um significado, ao contrário do que pressupõe o raciocínio arquitetural.

Com uma atitude guiada pela desconstrução, desregulamentação, disjunção, descontinuidade, deslocamento da relação entre significante e significado, entre forma e função, e, ao mesmo tempo, uma valorização do que se denomina entre, daquilo que está constantemente em processo, do transitório, do ambíguo, buscase uma transgressão dos valores históricos arquitetônicos e a abertura de outras possibilidades.

Mas, voltando à questão colocada no início, se a arquitetura lida com permanências, e estas estão estreitamente, ou pelo menos deveriam estar, vinculadas ao homem, não estaria esse homem fragilizando-se em meio a tantas indefinições, incertezas, dispersões e descentralizações? Talvez aqui resida uma das diferenças entre a literatura/filosofia, sobretudo as proposições de Barthes e Derrida e a arquitetura; como vimos, para Barthes, a escritura, ou a prática dos "textos de gozo", não determina nem revela um ser próprio, mas produz um sujeito em permanente crise e mutação, um sujeito "em processo". 
(13) CORBUSIER, Le. Por uma arquitetura. São Paulo: Perspectiva, 2002. Obra original: Vers une architecture; $A$ arte decorativa. São Paulo: Martins Fontes, 1996. Obra original: L'art décoratif d'aujoud'hui.

(14) TSCHUMI, Bernard. Le Fresnoy - Architecture in/between. Nova York: The Monacelli Press, 1999.

\section{VAZIOS CONSISTENTES}

Há muito tempo o programa é parte integrante do processo arquitetural. Suas exigências, aparentemente objetivas, sempre refletiram largamente culturas, costumes e valores particulares do meio social e da época, mas que não se traduziram, necessariamente, em formas precisas ou tipos ideais. Como exemplo poderíamos citar as gares ferroviárias, os grandes magazines, museus e galerias de arte do século 19, que abrigavam um programa complexo, mas não se vinculava, necessariamente, a uma forma precisa e ideal.

Ao contrário, era suficientemente flexível a ponto de provocar uma dissociação entre forma e conteúdo, como podemos comprovar por meio das incontáveis reciclagens de uso por que passaram essas edificações ao longo da história; muitas, por exemplo, abrigaram, e abrigam, funções, hoje, inadmissíveis para a época, servindo como contêineres, abrigos, de "eventos" arquiteturais.

Entretanto, com o advento do chamado funcionalismo e a busca de uma estreita correspondência entre os conteúdos e a forma (caráter?) - materializada em um novo discurso, sobretudo uma nova linguagem e sua pretensa universalização - a flexibilidade (alterações momentâneas da "natureza" do espaço) e, conseqüentemente, as possibilidades de manipulação e intervenção nesses espaços, por parte das pessoas, enfraqueceram-se.

Um ideário foi criado e, com ele, como vimos nos escritos de Le Corbusier, a formulação de um novo receituário de comportamento social, a fim de alcançar-se uma total integração entre sociedade e arquitetura ${ }^{13}$. As diferenças culturais regionais e nacionais seriam apagadas, em favor de um necessário ajuste social às novas demandas, às transformações, sobretudo tecnológicas, em curso e à "nova linguagem" da arquitetura. Seria realmente possível estabelecer uma relação de causa e efeito entre essa "nova linguagem", com suas formas precisas e ajustadas à "nova época", e as ações das pessoas no espaço proporcionado por essa arquitetura?

A própria história já nos mostrou que não, apesar de uma situação permanecer até os dias atuais - o desejo do arquiteto pelo controle e total definição do espaço, a busca por uma adequação entre forma e conteúdo e a apropriação social manifesta, seja ela no âmbito do edifício ou da cidade, ou o que poderíamos chamar de uma vinculação entre os significantes propostos e os significados surgidos.

Distante dessa preocupação, ao contrário, presenciamos, hoje com mais freqüência, o florescimento de acontecimentos, verificados nas mais diversas escalas, que rompem com o originalmente proposto, "excedendo", pela utilização, os usos e funções inicialmente previstos; desde "alpinistas" de pontes e escadas, passando pelas escadarias urbanas que se transformam em praças (ágoras momentâneas) de contemplação ou local de encontro e conversas (Figuras 5 e 6), às ruas, arcabouços de todo tipo de atividade, como lembra Bernard Tschumi ao citar Les evénements de Paris ${ }^{14}$, em 1968, e as barricadas dos estudantes nas ruas como um exemplo de rompimento da relação entre forma e conteúdo proposto, ou seja, da relação local-destinação imaginada. 

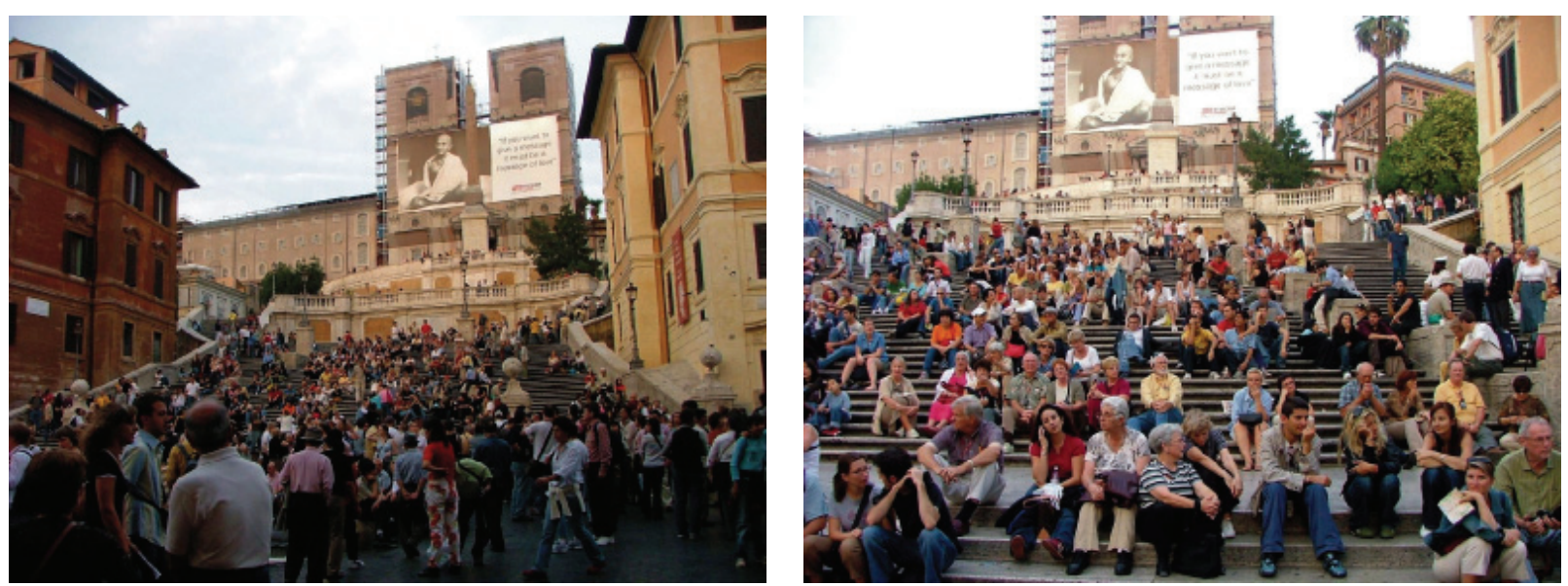

Figuras 5 e 6: Piazza di Spagna. Escadaria - Espaço suporte - Reprogramações. Praça Roma, Itália Fotos: Ana Villanueva

(15) FOUCAULT, Michel. Of other spaces. Diacratics 161 , springs. Paris, 1986.

(16) DERRIDA, Jacques. Psyché: Invention de l'autre. Paris: Galilée, 1983, p. 15.

(17) DELEUZE, Gilles ; GUATTARI, Felix. Bergsonism. Nova York: Zone Books, 1997, p. 97

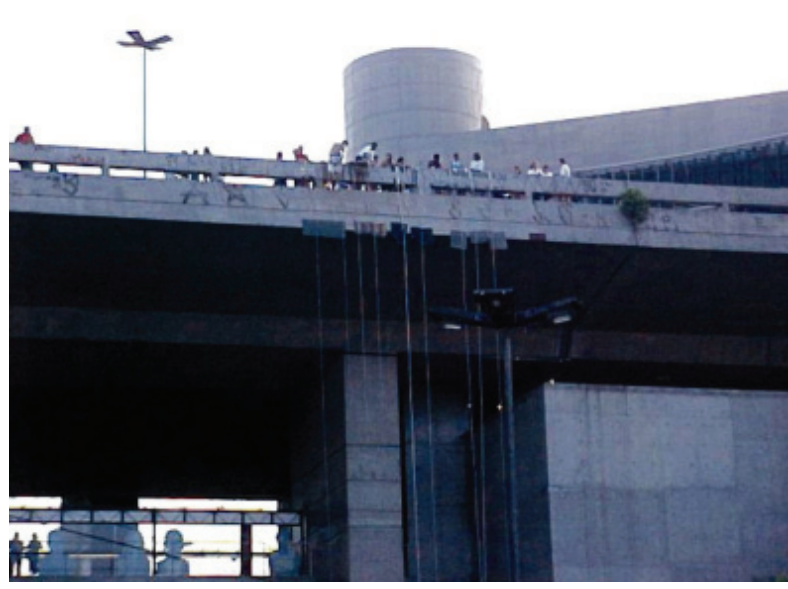

Figura 7: Viaduto da avenida Sumaré, São Paulo.

Espaço suporte -

Reprogramações. Praça esportiva São Paulo

Foto do autor
Nota-se que, para os desconstrucionistas, o fazer arquitetônico atual está diretamente vinculado às questões relativas ao espaço e não em relação à busca por novas formas ou linguagens formais per se; falam, inclusive, em uma nova racionalidade, uma nova intuição de espaço enquanto um meio (inter)ativo, formado por eventos (leia-se, profusão de elementos e acontecimentos imprevistos, por vezes ambivalentes ou bivalentes, de apreensão e leitura nãoimediata) adjacentes e remotos, alavancando rotinas e lógicas outras e adversas, processo o qual denominamos contaminações constitutivas.

Esse espaço seria aquele que construímos para nosso habitar, e onde, para Foucault ${ }^{15}$, "sempre nos tornamos algo diferente do que somos", ou para Derrida ${ }^{16}$, "onde se criaria a possibilidade de chegada de algo que não nos deixaria os mesmos", ou ainda, para Gilles Deleuze, "onde se daria a possibilidade de ocorrência do "virtual", ou seja, a realidade da qual ainda não possuímos o conceito"17. Em suma, seria no espaço, não no espaço 
(18) Cf. DERRIDA, Jacques. Khôra. Paris: Éditions Galillée, 1993

(19) Cf. DERRIDA, Jacques. Khôra. Campinas: Papirus, 1995, p. 19. predeterminado, mas nos "entres", nos espaços livres de préconfigurações, que vivenciaríamos estes "momentos de invenção" e criaríamos condição para o devenir autre, indo além dos limites impostos pelo "natural" (é possível falar do que seria próprio de um "lugar"?), pela história construída por discursos dominantes.

Eventos, invenção, devenir autre, termos direta e concomitantemente vinculados à busca de uma desregulamentação normativa da arquitetura, de seus sistemas de valores baseados em estreita ligação causal entre programa (conteúdo) e "tipo" - mais especificamente os estudos tipológicos que sempre conduziram a arquitetura a uma busca dos "tipos ideais" (universais?) de edifícios, de formas "adequadas" a seus conteúdos - e a uma conceituação e valorização do entre, do espaço intermediário, para os desconstrucionistas.

Assim, ao contrário de "tipos ideais", enquanto sintaxes a serviço de um discurso e doutrina funcionalistas, teríamos também o espaço do "não-desenho", ou do desenho não claramente determinado, organizado e ordenado (higienista?), da neutralização dos sentidos ou significados apriorísticos desse espaço, o espaço aberto às interpretações e apropriações múltiplas e nãocorrespondentes, um espaço suporte capaz de absorver e registrar as marcas deixadas, sem, no entanto, adquirir um sentido que pudesse ser adotado como o mais adequado, e, no momento seguinte, capaz de voltar à sua situação de significante, à espera de novos significados, interpretações, intervenções por parte das pessoas. Poderíamos falar de um espaço baseado mais em acumulação que composição, um espaço urbano como uma máquina produtiva livre das intenções primárias do autor, permanecendo apenas como traço demarcador sempre aberto à aceitação e pronto para fecundar, Khôra ${ }^{18}$.

Novamente, a relação com a filosofia da desconstrução, de Derrida, mais especificamente com o "revisado" conceito de Khôra. Para Derrida, este "seria uma região, um receptáculo, que passaria a ter uma forma a partir de interpretações externas, que deixariam nela a marca esquemática de sua impressão e de sua contribuição. Apesar disso, Khôra jamais se deixaria sequer atingir ou tocar, e, sobretudo, não se deixaria esgotar por esses tipos de tradução trópica ou interpretativa; Khôra seria capaz de adquirir as mais diversas formas, mas ao mesmo tempo capaz de permanecer em sua condição original"19. Não seria esse, justamente, o princípio do entre na arquitetura, um espaço "em condições" de assimilar as constantes e diferentes interrogações e requisições que, eventualmente, possam surgir a partir dos usuários?

Não que para os desconstrucionistas não deva haver um programa, incorrendo no risco do que poderíamos chamar de um desenho autônomo, no qual a não-pré-significação seria a justificativa para uma total indefinição espacial, formal, ou ausência de comprometimento do arquiteto com os problemas a serem enfrentados e solucionados.

O espaço intermediário seria compreendido, aqui, justamente como uma indefinição, um espaço aberto às significações entre espaços definidos, os quais seriam os agentes catalisadores, motivadores dessas ações dos usuários, desses eventos, desses acontecimentos inesperados, que surgiriam e permaneceriam sempre em processo, transitórios, jamais se firmando como atividade dominante a qual pudesse se transformar em convenção de uso, e onde o programa não 
(20) NIETZSCHE, Friedrich. Ecce Homo: Como alguém se torna o que é. São Paulo: Companhia das Letras, 1985. Obra original: Ecce homo: Wie Man wird, was Man ist; Humano, demasiado humano. Um livro para espíritos livres. São Paulo: Companhia das Letras, 2000. Obra original: Menschliches, Allzumenschliches. Ein Buch für freie Geister.

(21) Cf. Barthes, Roland. Le plaisir du texte. Paris: Éditions du Seuil, 1973, p. 15.

(22) Cf. BARTHES, Roland. $O$ neutro. São Paulo: Martins Fontes, 2003. Obra original: Le neutre.

(23) Não podemos nos esquecer que, como já foi dito, a arquitetura é construção, sendo impossível, portanto, a completa ausência.

(24) BATAILLE, Georges. Erotismo. Tradução de Claudia Fares. São Paulo Arx, 2004. Original: L'erotisme. Paris: Les Éditions de Minuit, 1957.

(25) La differáncepalavra-modelo que busca remarcar e afetar de diferência - produção de diferenças "conceituais" por deferimento e diferimento - os termos/ palavras propostos na história da metafísica na posição de significado transcendental, verdadeiros. Em uma entrevista à Julia Kristeva, diz Derrida: "A différance é o jogo sistemático das seria determinado pelo arquiteto, mas, mutável, estaria sempre sendo solicitado e conformado por essas ações. O papel do arquiteto residiria, creio, na tentativa de promover uma interação entre o definido e o não-definido, o desenho e o não-desenho, o inteligível e o não-inteligível, enfim, na criação de condições para esses eventos poderem surgir, ou intensificar-se, pelo estabelecimento de tensões mais do que concatenações hierárquicas, entre programas e ambiências urbanas, entre cruzamentos programáticos (intertextualidade), entre fluxos e vazios.

Em busca da constante definição dos espaços, de seus conteúdos e, conseqüentemente, de formas precisas, acabam sendo criados, pela repetição, modelos de usos para esses espaços, levando a um certo condicionamento quanto à utilização, movimentação e apropriação desses espaços, por parte dos usuários. Dirigidas por espaços com utilização predeterminada, aceita como natural e inexorável pelo processo histórico, as atitudes, gradativamente, foram sendo incorporadas e tratadas como intrínsecas a esses espaços; os acontecimentos inesperados, o que Derrida denomina de "eventos" e o rompimento com o "natural" representariam, justamente, uma tentativa de afirmação, de "vontade de poder", seguindo Nietzsche, como revelando um prazer em dizer não às simplificações, às oposições e valores culturais, psicológicos e históricos, "apropriados" ou não, "adequados" ou não20.

Retornando a Barthes, em Le plaisir du texte, o termo jouissance, ou as jouissances de um texto, está relacionado ao significante, à idéia de ruptura, ao discurso incompleto, reversível, ambíguo e o texto, ao contrário de conter a frase acabada como modelo, seria "um arremesso incessante de palavras, um exercício de infra-linguagem"21. Infra-arquitetural, pois não possui uma linguagem ou desenho definido, ocupando uma posição intermediária entre espaços definidos e "dominantes", ou um significado apriorístico, permanecendo, como Khôra, em estado de significante, em latência, à espera de "eventos" - o entre, o espaço intermediário, a linha-traço - ao invés da linhadiscurso, pois sugere neutralidade e não intencionalidade determinista -, seria esse momento, na arquitetura, momento de invenção, a configurar-se como espaço da jouissance, um local fértil para o excesso, o prazer de ir além do "natural" ou do estipulado, para o exercício do conflito, no qual nos distanciaríamos daquilo que somos e abriríamos espaço para o advento do outro, do porvir, conforme Derrida22.

Ainda, como nas escrituras de Barthes e Derrida, em que o autor está "morto", permanecendo o texto e as palavras livres de significado e sentidos incorporados, o entre em arquitetura seria um lugar onde se pode dizer que o arquiteto-autor estaria (quase) ${ }^{23}$ morto, pois o espaço, livre dos significados e representações advindos das intenções do arquiteto, estaria constantemente aberto às significações e resignificações por parte dos usuários criadores - os usadores. Ao possibilitar o entre, o arquiteto não estaria justamente contribuindo para o florescimento dessa atitude questionadora, ativa, estimulando, por essa "neutralidade" - um paradoxo? - formulações outras, para além do habitual, e uma postura de ir além do estipulado, do determinado pela repetição histórica por parte das pessoas? 
diferenças, dos rastros de diferenças, do espaçamento (spacing) pelo qual os elementos se remetem uns aos outros. Esse espaçamento é a produção, ao mesmo tempo passiva e ativa, dos intervalos (sem grifo no original) sem os quais os termos plenos não significariam, não funcionariam. "DERRIDA, Jacques. Posições

(Positions). Belo Horizonte: Autêntica, 2001, p. 32-33.

(26) "le plaisir du texte, c'est ce moment où mon corps va suivre ses propres idées - car mon corps n'a pas les mêmes idées que moi." Idem, ibidem, p. 27. Tradução livre do autor.

(27) Mais

especificamente, spacing é um termo sugerido pela primeira vez por Derrida e discutido sobretudo na obra Enlouquecer o subjétil com referência à escritura, como forma de diferenciar esta do que ele denomina de uma escritura arquitetônica. Derrida diz que a escritura arquitetônica implicaria em uma condição de leitura inventiva do espaço, ou seja, a possibilidade de uma leitura não-convencional, inexistente até então. Seria a leitura de um sujeito que não se limitaria a mover-se pelo espaço conforme

predeterminações ou sugestões projetuais, mas que, por uma atitude emancipadora, procura transformar e transgredir condições estabelecidas, previsíveis e habituais. Ver DERRIDA, Jacques; BERGSTEIN, Lena.

Enlouquecer o subjétil (Forcener le subjectile). São Paulo: Unesp, 1998. Obra original: Forcener le subjectile, 1986.
Sobre o excesso e o prazer, em seu livro Erotismo ${ }^{24}$, George Bataille diz ser preciso diferenciar o excesso de prazer do prazer do excesso. O prazer do excesso, de jouissance, talvez pudesse ser traduzido aqui como a possibilidade de manifestação dos desejos do usuário, muitas vezes distante do pretendido pelo arquiteto e dele próprio, passando de uma imaginação reprodutora para uma imaginação criadora.

Ou seja, entendendo-se aqui a imaginação reprodutora como algo atrelado ao fazer acrítico cotidiano e a imaginação criadora como algo relacionado ao pensar, refletir crítico, o excesso, para nós, o desejo do excesso, poderia ser tomado, aqui, como um momento necessário nesse processo de rompimento com a história, com a realidade que nos é apresentada.

Isso implicaria, em nosso caso, em um rompimento com associacionismos históricos (as formas dos espaços justificadas por seus usos, e essa relação causal se transformando em hábitos e senso comum, plenamente justificados pela prática ao longo do tempo), com as "verdades" da linguagem arquitetônica - a forma do espaço e seu significado condicionando usos e atitudes, produzindo os estereótipos e convenções - e abrindo a possibilidade da diferença, do processo constante de diferenciação - como o conceito de différance ${ }^{25}$ de Derrida, pela intensa experiência do espaço e, conseqüentemente, a possibilidade do contato com o Outro, entendendo-o não apenas como o próximo, mas aquilo em que estamos nos tornando ou em vias de tornarmo-nos (ipseidade), ainda não-consciente; como diz Barthes, "o prazer do texto é este momento onde meu corpo vai seguir suas próprias idéias, porque meu corpo não tem as mesmas idéias que eu"26. Talvez possamos substituir o termo texte por architecture, mais especificamente a condição spacing ${ }^{27}$ da arquitetura, expressa aqui pelo entre, pelo que não é nem presença nem ausência absolutos (suporte), mas espaço gerador de diferenças e da alteridade.

Mesmo em períodos inicialmente contrários a esse posicionamento e propícios a uma revisão desses valores, historicamente, as arquiteturas dominantes de diferentes períodos, destacando aqui a arquitetura funcionalista do movimento moderno, sempre foram vistas e entendidas como conjuntos de regras rapidamente transformadas em convenções, porque estáveis e, quase invariavelmente, gerais, baseadas na utilidade, em uma cultura do utilitarismo/funcionalismo; além da necessidade dessa arquitetura, como instituição social, de sempre se validar ou de explicar-se por intermédio de sua utilidade.

Talvez, também em função disso, a arquitetura moderna tenha se tornado limitadora ao necessitar estabelecer vínculos entre a forma e o conteúdo, "sugerindo", com isso, indiretamente, modelos de ações mais apropriadas ao conjunto formado. Oportuno momento para uma indagação: criticada, essa relação linear entre forma e conteúdo, quais as possíveis conseqüências do rompimento dessa lógica?

Em teoria, o conceito entre parece possibilitar o rompimento com essa "cultura" - o deslocamento do foco para a importância do espaço e para a potencialização de ações imprevistas - o fazer a partir de contínuas des e reprogramações espaciais e programáticas. 


\section{URBANISMO INFORMAL}

Normalmente desterritorializados, nadificados, ou reterritorializados de forma a torná-los espaços exclusivamente voltados ao comércio, ao consumo, à atividade monofuncional, esses espaços residuais e expectantes sob os viadutos, espaços entre, adquirem um novo significado com a construção e manifestação dessa máquina social sob o viaduto do Café. Configura-se, ali, uma nova situação de espaço coletivo urbano com uma ação voluntária (clandestina, mas extremamente potente) a qual, como já foi dito, mina e rompe com as representações apriorísticas de um espaço, possibilitando um espaço de jouissance ao estimular o excesso, o além do imaginado e do que poderia ser próprio para determinado local.

Assim, uma questão está colocada e, acredito, deve ser considerada e pensada. Em qual medida a submissão de uma possível ação, seja ela colocada por arquitetos ou população, a representação, seja do que parece ser a essência de um lugar urbano, não fragilizaria essas ações sobre esse local ? Explico-me. Seria possivel pensarmos em reconceituações e rupturas mais profundas e, com isso, reterritorializações outras, em espaços urbanos que já possuem uma forte representação histórico-social? Tensões programáticas obtidas por associações inusuais de atividades - intertextualidade - seriam uma possível estratégia para a destruição ou superação de uma representação histórica capaz de condenar um lugar a uma identidade negativa a qual, muitas vezes, sugere ações frágeis, equivocadas, convencionais, justamente por seguirem o que sempre pareceu ser o mais adequado e ajustado àquele lugar?

Microações espontâneas e informais, capazes de constituir algo além do previsto e do usual para determinado lugar; ações micropolíticas iniciadas pelo desejo e compromisso de alguns "inquilinos clandestinos" urbanos, trabalhadas e potencializadas pela arquitetura, seriam capazes de iniciar um outro porvir urbano e enunciar (os agenciamentos espaciais de enunciação) uma outra possibilidade de urbanização e administração de áreas consideradas em situações limite e ingovernáveis?

A cidade contemporânea expressa as angústias e ansiedades emergentes do curso regulador e normativo da globalidade, de forma tão exacerbada quanto maior a complexidade que elege, cunhando o objeto que the responde de forma eficaz às demandas de seu padrão: forma, domínio, o fashion dos templos e ícones da pósmodernidade. Torna-se premente explorar os interstícios dessa cultura e sublinhar contrapontos de um novo pensamento, a importância de pensar-se estratégias a frisarem culturas da exaltação do fazer coletivo, espontâneo, agregador e emancipador.

Rever e repensar relações do homem com a paisagem edificada e do homem com seu produto maior, a cidade, pensar (sobre) o espaço, "espaçamentos" urbanos que expandam a escala do objeto, potencializem o fazer coletivo, espontâneo, criativo, interpretando a qualidade do vazio enquanto extensão do objeto não-aprisionado ao pragmatismo da forma e do domínio.

Conceitua-se essa disposição do novo fazer à qualidade do "entre", ruptura do restrito, formal, do programado e pragmático, "cultura" do espaço imaginário, do espaço em transformação e do porvir, da escala de quem faz e não do que a função restrita programa ou determina. 
Há, portanto, nesse entreato cultural, a tentativa de estabelecer relações cruzadas e fusões com o pensamento pós-estruturalista (novamente a intertextualidade) como estratégia para se pensar o espaço da cidade e, com isso, a possibilidade de "dar passagem" ao ressurgimento de valores de humanidade, baseados não no humanismo clássico, metafísico, criticado por Derrida, mas talvez um humanismo práxis - cultura como prática da vida, como vida realizada - vital ao futuro da cidade e do próprio homem e sua errática vontade criativa, emancipadora. Iteração e alteração ao mesmo tempo; não apenas (mas também) aceitação do designado pelo objeto e suas destinações, mas interrogação e solicitação permanente (o indecidivel, do qual nos fala Derrida) do "suporte" para uma verificação de sua capacidade de responder e acolher-nos em nossas intenções, intensas-ações.

\section{Bibliografia}

BARTHES, Roland. Essais critiques. Paris: Éditions du Seuil, 1964.

_. Le plaisir du texte. Paris: Éditions du Seuil, 1973.

—. O neutro. São Paulo: Martins Fontes, 2003.

BAUMAN, Zygmunt. Amor liquido: Sobre as fragilidades dos laços humanos. Rio de Janeiro: Jorge Zahar Editor, 2004

BENJAMIN, Andrew. Distancing and spacing. Archictetural design. Philosophy \& architecture. Londres: Academy Editions, 1990.

BLANCHOT, Maurice. Le livre à venir. Paris: [s.n.], 1959.

CORBUSIER, Le. Por uma arquitetura. São Paulo: Perspectiva, 2002.

_. A arte decorativa. São Paulo: Martins Fontes, 1996.

DELEUZE, Gilles; GUATTARI, Felix. Mille plateaux. Capitalisme et schizophrénie. Paris: Les Editions de Minuit, 1980

_. Conversações. Rio de Janeiro, Editora 34, 1992.

_. Bergsonism. Nova York: Zone Books, 1997.

_. Empirismo e subjetividade: Ensaio sobre a natureza humana segundo Hume. São Paulo: Editora 34, 2001.

DERRIDA, Jacques. Gramatologia. São Paulo: Perspectiva, 1973.

_. Khôra. Paris: Éditions Galillée, 1993.

_. L'archéologie du Frivole. Paris: Éditions Galillée, 1990

_. La vérité en peinture. Paris: Flammarion, 1978.

L'écriture et la différence. Paris: Le Seuil, 1967.

DERRIDA, Jacques; BERGSTEIN, Lena. Enlouquecer o subjétil. São Paulo: Unesp, 1998.

DERRIDA, Jacques; ROUDINESCO, Elizabeth. De que amanhã. Rio de Janeiro: Jorge Zahar, 2004.

EISENMAN, Peter. Diagram diaries. Londres: Thames \& Hudson, 1999.

EISENMAN, Peter. Processos de lo intersticial. El Croquis, Madri: El croquis, p. 21-35, 1997.

An architectural design interview by Charles Jencks. Architectural Design Deconstruction in Architecture, Nova York: Academy Group LTD, v. 581998.

FOUCAULT, Michel. Of other spaces. Diacratics 16 1, springs. Paris: [s.n.], 1986. 
KIPNIS, Jeffrey. P-Tr's Progress. El Croquis, Madri: El croquis, n. 83, p. 36-49, 1997.

LYOTARD, Jean-François. La condition postmoderne. Paris: Les Éditions de Minuit, 1979.

MERLEAU-PONTY, Maurice. Humanisme et terreur. Paris: Gallimard, 1947.

MOISÉS, Leyla Perrone. Texto, crítica, escritura. São Paulo: Ática, 1993.

NIETZSCHE, Friedrich. ECCE HOMO: Como alguém se torna o que é. São Paulo: Companhia das Letras, 1985.

_. Humano, demasiado humano. Um livro para espíritos livres. São Paulo: Companhia das Letras, 2000

SARTRE, Jean Paul. O existencialismo é um humanismo. São Paulo: Abril Cultural, (Coleção Os Pensadores), In: v. XLV, 1978

SOLA MORALES, Ignási. Diferencias. Topografias de la arquitectura contemporánea. Barcelona: Gustavo Gilli, 1995.

Territorios. Barcelona: Gustavo Gilli, 2002.

TSCHUMI, Bernard. Architecture and disjunction. Cambridge: The MIT Press, 1996.

Le Fresnoy - Architecture in/between. Nova York: The Monacelli Press, 1999.

WIGLEY, Mark. A desconstrução do espaço. Novos paradigmas, cultura e subjetividade. Porto Alegre: Artes Médicas, 1996.

ZAERA-POLO, Alejandro. La Maquina de Resistencia Infinita de Eisenman. El Croquis, Madri: El croquis, n. 83, p. 50-63, 1997.

Obs.:

Este texto é parcialmente resultante da tese de doutorado do autor, O(s) lugar(es) do entre na arquitetura contemporânea: Arquitetura e pós-estruturalismo francês. São Paulo: FFLCH-USP, 2005.

\section{Nota do Editor}

Data de submissão: agosto 2007

Aprovação: junho 2008

\section{Igor Guatelli}

Arquiteto, graduado em Arquitetura e Urbanismo, mestre em

Arquitetura pelo Programa de Pós-Graduação em Estruturas Ambientais Urbanas da Faculdade de Arquitetura e Urbanismo, doutor em letras modernas francesas pelo Programa de Pós-Graduação em Língua e Literatura Francesa da Faculdade de Filosofia, Letras e Ciências Humanas, da professor do Departamento de Projeto da Faculdade de Arquitetura e Urbanismo da Universidade Mackenzie.

Rua João Moura, 870, ap. 202 B. Pinheiros.

05412-002 - São Paulo, SP

(11) 91477441, (11) 30812143

igorguat@uol.com.br 